Openness to Faith as a Disposition for Teachers in Catholic Schools

ROBYn HORner (AUSTRALIAN CATHOLIC UnIVERSITY)

Didier Pollefeyt (KU LeUVen)

JAN BOUWENS (KU LEUVEN)

TERESA BROWN (AUSTRALIAN CATHOLIC UNIVERSITY)

ChristiaAn JACOBS-VANDEgEer (AUSTRALIAN CATHOLIC UNIVERSITY)

Maeve Heaney (Australian Catholic University)

Michael Buchanan (Australian Catholic University)

Research completed with the support of a Teaching Development Grant from Australian Catholic University. 


\title{
Openness to Faith as a Disposition for Teachers in Catholic Schools
}

\begin{abstract}
In the the Catholic Church, which includes in its mission the provision of school education, the significant rise of "no religion" in contemporary Western societies prompts serious new questions about how this mission can be lived out. An important response to this issue can be found in the Enhancing Catholic School Identity Project, which provides empirical evidence of the lived faith dispositions of members of Catholic school communities and recommends on both theological and cultural/contextual grounds the enhancement of Catholic school identity through the recontextualisation of faith in dialogue. We argue that the dispositions of teachers are a vital factor in the development of a Catholic Dialogue School. Using aggregated Enhancing Catholic School Identity Project data in Australia from 2011-2018, we use the example of teacher intentions versus student outcomes for a "Christian Values Education" approach to RE to illustrate the importance of a teacher disposition that is intentionally and explicitly open to Catholic faith. Moreover, reflecting historically on different approaches to RE in Australia, we argue that the capacity of religious educators to witness to faith-in addition to bringing a specialised knowledge of Christian and other faiths, and a capacity to moderate a dialogical classroom with sensitivity and respect-is key to students' understanding of faith as a living phenomenon.
\end{abstract}




\section{Openness to Faith as a Disposition for Teachers in Catholic Schools}

The Problem

For confessional schools in Western contexts, the role of teachers in promoting the formation of students in any particular faith tradition is a hotly contested issue. In Australia, this has reached a crisis point for many Catholic schools, where the distance between Christianity and culture has become such that not only students, but also many teachers question their identities in relation to the Church. This is a significant problem to the extent that the Church envisions the Catholic School as an educational community offering an evangelising and formative experience of Christian faith, and where the role of the religion teacher, especially, is seen as crucial in witnessing to that faith as radically personal and alive. ${ }^{1}$ This formative vision of Catholic schools is seen to depend on teachers who "fulfil a specific Christian vocation and share an equally specific participation in the mission of the Church, to the extent that 'it depends chiefly on them whether the Catholic school achieves its purpose'." ${ }^{2}$ While it is possible in the wake of the current crisis to imagine Catholic schools adapting to function in the way of many other Catholic agencies-where what is achieved by being Catholic is the provision of a type of service that prioritises particular values (service to the poor and vulnerable, maintenance of particular ethical positions, and so on)-this is not what is envisioned in Church documents, despite the fact that it is common in non-Western countries for Catholic educational institutions to be populated almost exclusively by non-Catholics. ${ }^{3}$

One response to the crisis has accompanied an increased "professionalisation" of Religious Education (RE), where the argument is that the teacher's individual perspective on faith is actually private and inconsequential. Another response has been to use proxies for the Catholic commitment of teachers (evidence of regular mass attendance at the employment interview) and students (primary school exit tests of Catholic knowledge) to ensure that schools adhere to a doctrinal approach in religion, which is set out in standardised text books. The first response reflects values of religious freedom and is highly pragmatic at a time when it is increasingly difficult to employ suitably qualified teachers, but it can seem at odds with the Magisterially-expressed purposes of

\footnotetext{
${ }^{1}$ Congregation for Catholic Education, The Religious Dimension of Education in a Catholic School: Guidelines for Reflection and Renewal (Vatican City: Liberia Editrice Vaticana, 1988), 6.

2 "The Catholic school participates in the evangelizing mission of the Church and is the privileged environment in which Christian education is carried out. In this way 'Catholic schools are at once places of evangelization, of complete formation, of inculturation, of apprenticeship in a lively dialogue between young people of different religions and social backgrounds.'" [Congregation for Catholic Education (for Seminaries and Educational Institutions), The Catholic School on the Threshold of the Third Millennium (Vatican City: Liberia Editrice Vaticana, 1997), 11. The internal quote is from John Paul II, Apostolic Exhortation: Ecclesia in Africa (Vatican City: Libreria Editrice Vaticana, 1995), 102].

3 Note, however, the argument against this reading in Richard Shields, "Gospel Values and Catholic Education: Revitalizing the Faith Community in a Culture of 'Whatever'," Religious Education 113, no. 1 (2018).
} 
Catholic schooling. The second response emphatically underscores a commitment to the confessional nature of the school, but its proxies are only that, proxies, and aside from the other issues they raise, do not actually demonstrate the existence or development of Catholic faith. Neither of these responses addresses the real issue about the capacity of teachers to engage with faith in support of the mission of the Catholic school. In order to understand that issue more clearly, we first need to consider the context in which those teachers find themselves.

The Context

It is widely acknowledged that the place of religion in Western societies has changed; we need only glance at census and similar data in the United Kingdom, Europe and Australia to see that "no religion" is fast becoming a majority-held position. ${ }^{4}$ While it is visible in the adult population overall, adherence to no religion is especially true of people under $30 .{ }^{5}$ In 2016 , Linda Woodhead reported that $60 \%$ of $18-24$ year olds in the United Kingdom identify as having no religion. ${ }^{6}$ Gary Bouma recently identified that $52 \%$ of Australian teenagers count themselves in the "nones." 7 What this data suggests is that the world of many young teachers and their students is one in which institutionalised religion has little place.

One way of thinking about the rise of "no religion" is to argue that societies are becoming more secularised. ${ }^{8}$ Secularisation is sometimes associated with the evident decline in participation in religious traditions that seems to appear as a natural correlate of modernity (the more modern we become, the less religious we are). The "New Atheists" argue for this understanding, although

\footnotetext{
${ }^{4}$ See the results of the 2013 British Social Attitudes Survey, cited in Linda Woodhead, "The rise of "no religion" in Britain: The emergence of a new cultural majority," Journal of the British Academy 4 (2016): 246. Similar results are reflected in the European Values Survey for a number of countries: https://www.europeanvaluesstudy.eu/files/Believing large.jpg. Nones in Australia became the largest category in the 2016 Census: Gary D. Bouma, "Census 2016 shows Australia's changing religious profile, with more 'nones' than Catholics," The Conversation (2017), http://theconversation.com/census-2016-shows-australias-changing-religious-profile-with-more-nones-thancatholics-79837.

${ }^{5}$ Nicola Madge and Peter J. Hemming, "Young British religious 'nones': findings from the Youth On Religion study," Journal of Youth Studies (2016): 3.

${ }^{6}$ Woodhead, "The rise of "no religion" in Britain: The emergence of a new cultural majority," 24.

${ }^{7}$ Gary D. Bouma, "Religion in Australia: What are the Implications of 'None' being the New Normal?," ABC Religion and Ethics (28 June 2018).

8 "In Australia, for much of its post-1788 history and including the lead up to Federation in the late nineteenth century, several scholars have claimed that the social reality of secularisation was at the expense of a public religious identity. They argued that the stronghold of secularisation was more direct and complete in Australia than elsewhere mainly because it was coupled with a sense of religious disillusionment arising from the failure of religious institutions to meet the intellectual and social challenges of the day." Michael Buchanan, "Exploring the Role of the Religion Teacher within the Context of a Faith-based Religious Education Approach," in Religion and Values Education: Contextual Challenges (UK: Peter Lang, 2019). See Wayne Hudson, Australian Religious Thought (Clayton, VIC: Monash University Publishing, 2016); Patrick O'Farrell, "The History of the New South Wales Labour Movement, 1880-1910: A Religious Interpretation," Journal of Religious History 1, no. 2 (1962); Allen Patience, "Australia's Hard Culture: Notes for an Historical Sociology," Australian Studies 14 (1990).
} 
they not only consider this decline to be a natural process, but also one to be actively encouraged. It is not surprising, then, that for people who promote religious institutions, secularisation is sometimes seen not as a neutral process but as the fruit of the ideology of secularism. For those who continue to espouse a religious point of view, secularisation is often seen as a threat that must inspire resistance, which is often formulated in terms of a call to return to traditional methods of catechetical instruction that here we call "Reconfessionalisation." Identifying this polarisation of views can help us to understand different anxieties present in society, although neither of these views is especially helpful as an explanation of what is happening in the West. On the one handagainst the secularists-religious traditions have not simply died out as expected. On the other hand-against those who would fight to reverse processes of secularisation-the fact that we already live in "a secular age," and that institutional religious traditions generally no longer enjoy a powerful or authoritative status, makes it especially hard to envisage any sort of going "back" to a time when religious institutions held authoritative sway. ${ }^{9}$

Another way of thinking about the context is to focus not so much on secularisation (which we understand here in the sense of a functional differentiation between Church and State), but on other processes that are influential in changing attitudes to religion in the modern West. ${ }^{10}$ These include the phenomenon of pluralisation, which refers not only to the existence of many different religious and other worldviews in closely lived proximity but also to the increased awareness we have of the apparent contingency of our religious choices and to the pressures that arise to choose between competing possibilities. ${ }^{11}$ Individualisation emerges as the relatively recent expectation of many in the West that their identities are to be personally crafted and not received from others, whether those others are family, religious communities, or societies more broadly. Identity formation becomes the discrete project of the individual, who is simultaneously subject to overwhelming market and media forces with regard to identity. Individualisation is related to the phenomenon of detraditionalisation, where it seems to become increasingly more difficult for families and communities to hand down their traditions and where individuals seek to forge their own paths. ${ }^{12}$ Detraditionalisation comes about because of a loss or fragmentation of communal

\footnotetext{
${ }^{9}$ Charles Taylor, A Secular Age (Cambridge, MA/London: Belknap Press of Harvard University Press, 2007$), 543$.

10 José Casanova, "Rethinking Secularization: A Global Comparative Perspective," The Hedgehog Review (2006): 7.

${ }^{11}$ Peter L. Berger, "The Desecularization of the World: A Global Overview," in The Desecularization of the World: Resurgent Religion and World Politics, ed. Peter L. Berger (Washington, DC/Grand Rapids. MI: Ethics and Public Policy Center/Eerdmans, 1999); The Many Altars of Modernity: Toward a Paradigm for Religion in a Pluralist Age (Berlin/Boston: De Gruyter, 2014). Australia was founded to be a secular (although religiously tolerant) nation. Commonwealth of Australia Constitution Act (1900), s116.

${ }^{12}$ Paul Heelas, Scott Lash, and Paul Morris, Detraditionalization: critical reflections on authority and identity (Cambridge, MA: Blackwell Publishers, 1996).
} 
memory, which can occur as an effect of globalisation, travel, migration, increased levels of education, media of all kinds, increased affluence, the rapid expansion of cities and so on. In this situation, religious symbols no longer function to unite but to disperse communities. ${ }^{13}$ This dispersion is intensified when members of religious traditions that were once authoritative and powerful in purporting standards of behavior and moral values are seen very publically to undermine those same standards and values.

From this broad sketch of social forces, we come to see that the rise of "no religion" is perhaps not simply a response to processes of secularisation or agents of secularism. It arises as the constellation of a number of events, changes and movements, and it needs to be sensitively addressed if one is seeking to promote an openness on the part of young people, in particular, to the possibility of transcendence and an interest in and appreciation or even love for a religious tradition. In the concrete situation of the Catholic Church, which includes in its mission the provision of school education, the rise of "no religion" prompts serious new questions about how this mission can be lived out.

An important response to this issue can be found in the Enhancing Catholic School Identity (ECSI) Research, which was first published in full in $2014 .{ }^{14}$ ECSI examines and interprets theologically aspects of the changing cultural contexts of Christian faith in Australian society, specifically in Catholic Schools. In its diagnostic phase, it uses surveys including validated scales to measure belief styles (the Post-Critical Belief Scale), identity preferences (the Melbourne Scale) and pedagogical approaches (the Victoria Scale). Its 'census' method involves sampling every school and every person: ECSI does not follow individuals, but cross-sectional cohorts over time. The research has been implemented in almost all Victorian Catholic schools and is increasingly being piloted or taken up in other dioceses in Australia as well as in other countries. One of its principal benefits is that it collects evidence about what is actually taking place in Catholic schools, and in response, enables a more nuanced proposal for ways in which the gap between Christianity and culture can be negotiated.

\footnotetext{
${ }^{13}$ Danièle Hervieu-Léger, "Religion as a Chain of Memory," Nova Religio: The Journal of Alternative and Emergent Religions 8, no. 3 (2005).

${ }^{14}$ Didier Pollefeyt and Jan Bouwens, Identity in Dialogue: Assessing and Enhancing Catholic School Identity. Research Methodology and Research Results in Catholic Schools in Victoria, Australia (Berlin: Lit Verlag, 2014).
} 
Below, we present and interpret previously unpublished, consolidated Australian ECSI data from 2011-2018. ${ }^{15}$ The evidence shows that up to half the teachers in Catholic schools are struggling to make meaningful connections between Catholic faith and the contemporary context. The first three figures refer to evidence gleaned from the Melbourne Scale using the following constructs:

- Confessionality, which is the extent to which traditional Catholic symbols and practices are perceived as meaningful in the school environment;

- Reconfessionalisation, which refers to the active strategy of reinforcing Catholic school identity in spite of a secularising cultural context, presenting Catholic faith to students in terms that are largely evangelising and catechetical;

- Secularisation, which is a severance of school ties to religious faith and the Catholic Church;

- Christian Values Education (CVE), a correlational approach where schools promote the values in common to both Christianity and culture; and

- Recontextualisation, where schools aim to embody and articulate Catholic teaching in dialogue with other religions and worldviews present in the context. ${ }^{16}$

The graphs show scale means both at the descriptive level (blue) and the normative level (green). ${ }^{17}$ Confessionality is reported only at the descriptive level. Companion "traffic light" charts are used to show percentages. The constructs do not map cleanly onto methods of teaching RE, but inform approaches to the Catholic identity of each school or grouping as a whole. The value of looking closely at this evidence is that we see a profile of all teachers in Catholic schools in terms of how they perceive the current identity of their school and how they would like to see the identity of their school in the future. Comparing this with student perceptions and desires then helps us to understand the interactions between staff and students on these important questions.

\section{Staff Results}

Figure 1 shows results of 39,408 Australian school staff members from Melbourne Scale surveys completed up to October 2018.

\footnotetext{
${ }^{15}$ Results from the Enhancing Catholic School Identity project published with kind permission of Catholic Education Offices in the dioceses of Adelaide, Ballarat, Brisbane, Cairns, Melbourne, Parramatta, Port Pirie, Rockhampton, Sale, Sandhurst, Townsville, and Toowoomba.

16 The constructs were first characterised in Lieven Boeve, "The Identity of a Catholic University in Post-Christian European Societies: Four Models," Louvain Studies 31, no. 3 (2006): 238-58.

17 Participants responded to a series of statements using a 7-point Likert scale (from to strongly agree to strongly disagree), where 4 is the turning point from acceptance to rejection.
} 

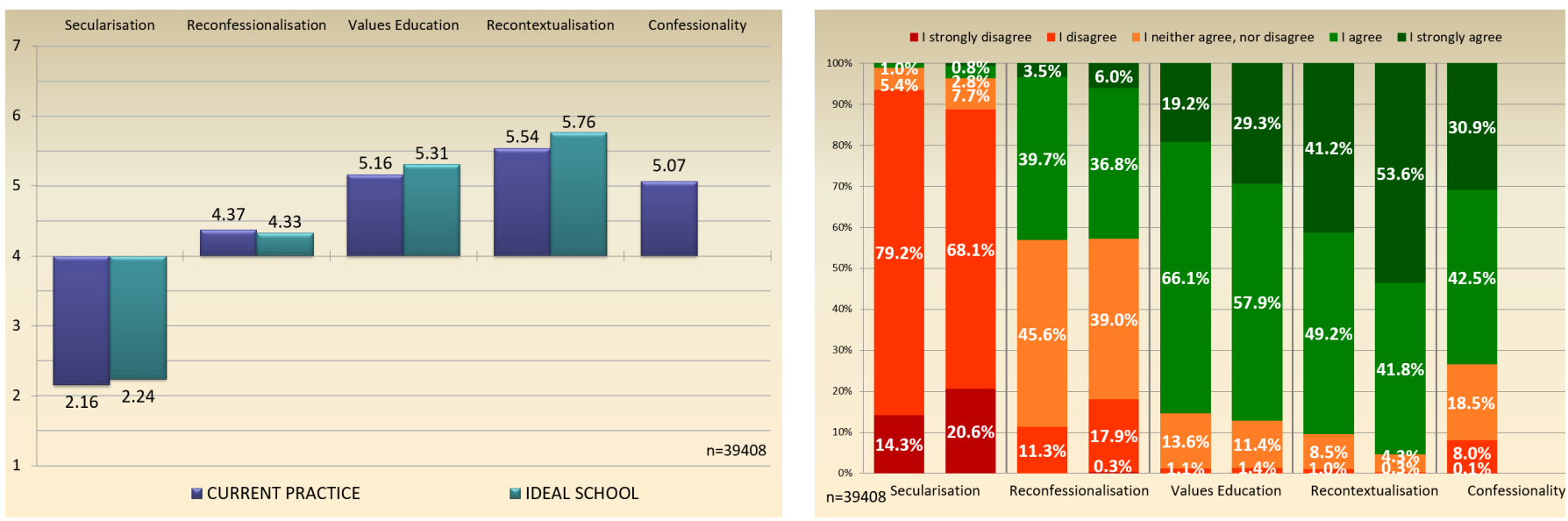

Perceived Confessionality is just above $5 / 7$ : this is clearly above the doubt zone $( \pm 4)$, the teachers perceive a significant number of references to the Catholic faith tradition in daily school life: symbols, Bible quotes, crucifixes, prayer, RE, artwork, pastoral care, priests at school, et cetera. Resistance to Secularisation is very strong. Comparing the descriptive with the normative results, however, we see a very slight lessening of resistance to Secularisation in the ideal school. Notwithstanding this, the staff are committed to not allowing their school to secularise. They recognise strong levels of Recontextualisation as present, indicating a slightly increased preference for it at the normative level. Recontextualisation is clearly perceived as the dominant pattern in the current practice, as well as the most strongly desired way forward. At the same time, the preference for Reconfessionalisation is in the doubt zone, so that it is not strongly perceived, and support for it lessens marginally. This reads well in connection with the support for Recontextualisation. Of concern, however, is the high and rising staff preference for CVE, since evidence from student data shows that this leads to Secularisation.

A preference for CVE could be explained by staff demographics: it may have been a relatively successful strategy in the 1970s and 1980s when the gap between Catholicism and culture was not so wide. Perhaps support for CVE comes about because this has been the approach of older staff, and there has been little genuine reform of the thinking behind this strategy. Very often, staff members genuinely believe that CVE will lead to the reconfessionalisation of students. At the same time, CVE is the least demanding approach to Catholic identity and RE. Some teachers, who mostly but not necessarily belong to a younger generation of staff, teach RE by leaning on the formal features of CVE: they focus on the shared values but disregard the religious teachings. Their students eagerly follow - and the four critiques of CVE apply (that is, it is ineffective, predictable, counterproductive, and reductive). CVE does not evince from these staff members any personal 
commitment to the Catholic tradition; in fact, it is a safe harbour for those who feel uncertain about their own faith or disenfranchised by the Church. All it requires is the capacity to identify values that are held in common between Catholicism and culture, common values-that is, values that are universal rather than particular. With the Christian rationale for and articulation of these values kept silent, no staff member is ever required to articulate more than a positive humanism.

\section{Primary School Results}

Now we consider the responses of students in light of what teachers are doing. First, we look at children in primary school, all of whose classroom teachers, under normal conditions, teach them RE. In Figure 2 (below) we see results of 46,212 Australian grades 5 and 6 students, from Melbourne Scale surveys completed up to October 2018.

Figure 2: (C) Pollefeyt \& Bouwens KU Leuven 2018
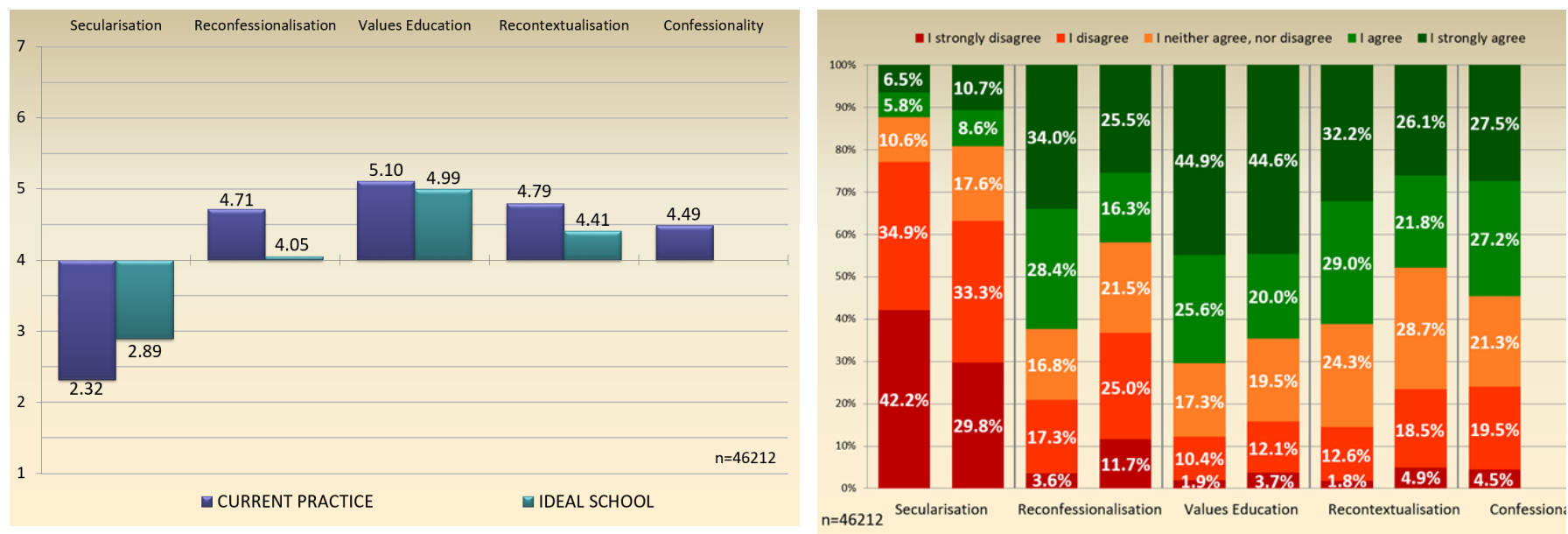

Perceived Confessionality is just under 4.5/7, meaning that many of the children-albeit not allare able to perceive that the classical characteristics of Catholic education are present in their primary school, to various degrees. Resistance to Secularisation is strong (2.89/7). Comparing the descriptive with the normative results, however, we see a lessening of resistance to Secularisation in the ideal school. Senior primary students recognise strong levels of CVE as present at the descriptive level, indicating a slightly decreased preference for it at the normative level. This is concerning, because it leads to Secularisation, and while support for it decreases, it does not drop away at all. CVE is an 'easy' approach to RE for students, because the answers are always predictable and there need not be any real engagement with the Christian tradition. It is a hopeful sign, though, that these students recognise Recontextualisation as present. They also support it on the normative level, although in a less confident way. While the children are not against Recontextualisation, they seem to adopt a somewhat reluctant stance. Troubling to note is that students recognise about as 
much Reconfessionalisation as they do Recontextualisation in the school. Present-day children experience that Catholic primary schools in Australia are eager to Reconfessionalise, more than the school staff suspect. This also influences the way in which Recontextualisation is being shaped. A school's focus on proclaiming and preserving the Catholic faith tradition (Reconfessionalisation) may well outweigh its desire to enter into a genuine dialogue with the contemporary cultural context (Recontextualisation). On the normative level, the students are wary of this, though, as their support for Reconfessionalisation wavers (4.05/7).

\section{Secondary School Results}

In Australian secondary schools, there are generally two models according to which RE workload is allocated. According to the first model, teachers with greater interest or specialisation in RE teach the RE load. According to the second model, almost any teacher in the school can potentially be timetabled to teach RE, perhaps to reinforce a pastoral relationship between a class and a teacher, or to allow for flexibility in the timetabling or load allocations, or because there are insufficient specialists in the area. While there are generally requirements in place in Australian dioceses for the accreditation of teachers to teach RE, it is not universal that teachers have this accreditation or, indeed, any specialisation, and it is ultimately up to the school as to whether there is any requirement for a teacher to be Catholic. The reality of the situation is that teacher expertise in other areas of the curriculum is often the primary concern in staffing. Difficulties in finding suitably qualified teachers more broadly increase in relation to school location, so that schools in outer urban, rural and remote areas frequently find it hard to attract teachers in specific subject areas. 
In Figure 3 (below) we see results of 77,127 years 7-12 Australian students from Melbourne Scale surveys completed up to October 2018.

Figure3: (C) Pollefeyt \& Bouwens KU Leuven 2018
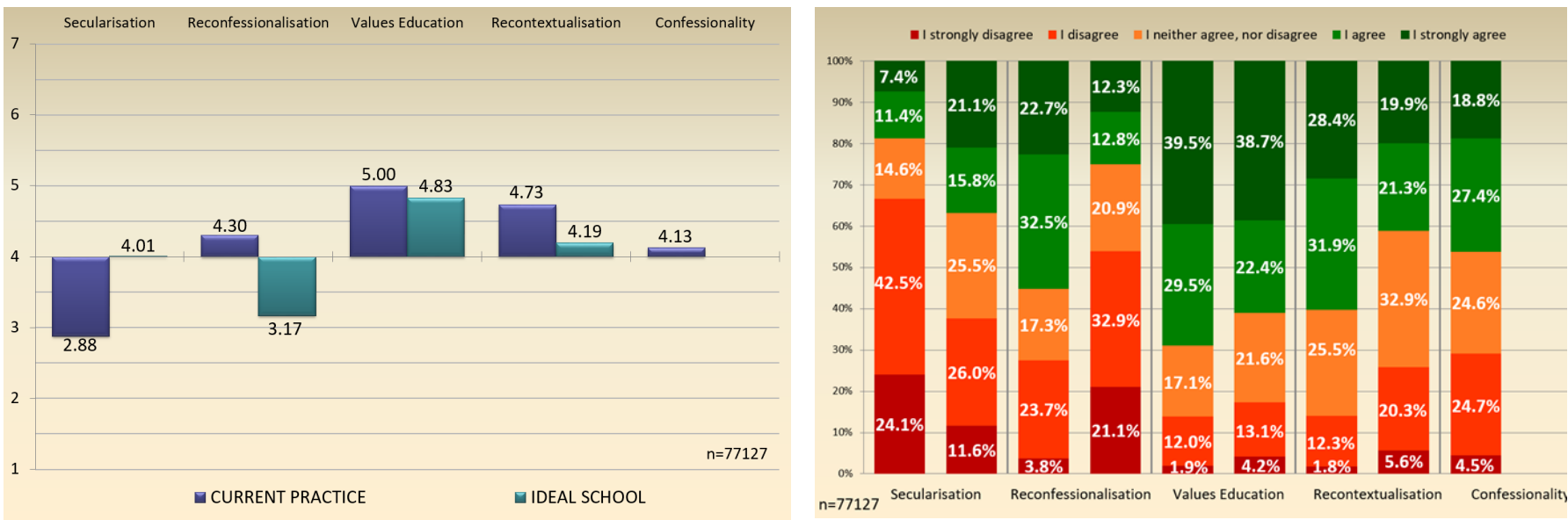

Perceived Confessionality is just over $4 / 7$, which is lower that of the school staff or the primary school children. This means that the secondary college students do not strongly recognise or find meaning in the explicitly Catholic religious elements in the school. Although the school's Confessionality has not yet vanished entirely, it is certainly disappearing. Continuing to establish a Catholic identity that is based on remnants of the past becomes a decreasingly viable option. The denial of Secularising tendencies at the descriptive level is quite strong. Compared to the normative results, however, we see the complete reduction of resistance to Secularisation in the ideal school. There is a significant gap between the perceived Catholic profile of the school and the kind of school the students would prefer. A growing minority would choose for the school to let go its Catholic identity, while others would like to see it remain. Students recognise strong levels of CVE as present at the descriptive level. This is concerning, because this correlates to the rise of Secularisation, and while support for it decreases at the normative level, it does not drop away dramatically. We can suggest, once again, that the support for CVE may be because it is the easiest option for students. It is convenient to support an education in generally shared values, but to drop the religious background of those values. At the same time, students recognise Recontextualisation as present. Although support for it decreases at the normative level, it remains positive overall. Neither primary nor secondary students are against Recontextualisation, but they are cautious about it. The secondary students perceive some Reconfessionalisation in the school, but at the normative level, Reconfessionalisation is actively rejected. Clearly, attempting to impose Catholic teachings and practices upon this generation of students would be less than effective. In fact, it would provoke explicit resistance to such an extent that it would render the strategy counter-productive. 


\section{Support for CVE}

The consolidated Australian results show that there is a commonality between staff and students in support for CVE. This is demonstrated even more clearly when the normative results for the four subpopulations are converted to percentages and shown using the explanatory diagram used to depict the Melbourne Scale (Figures 4 and 5, below).

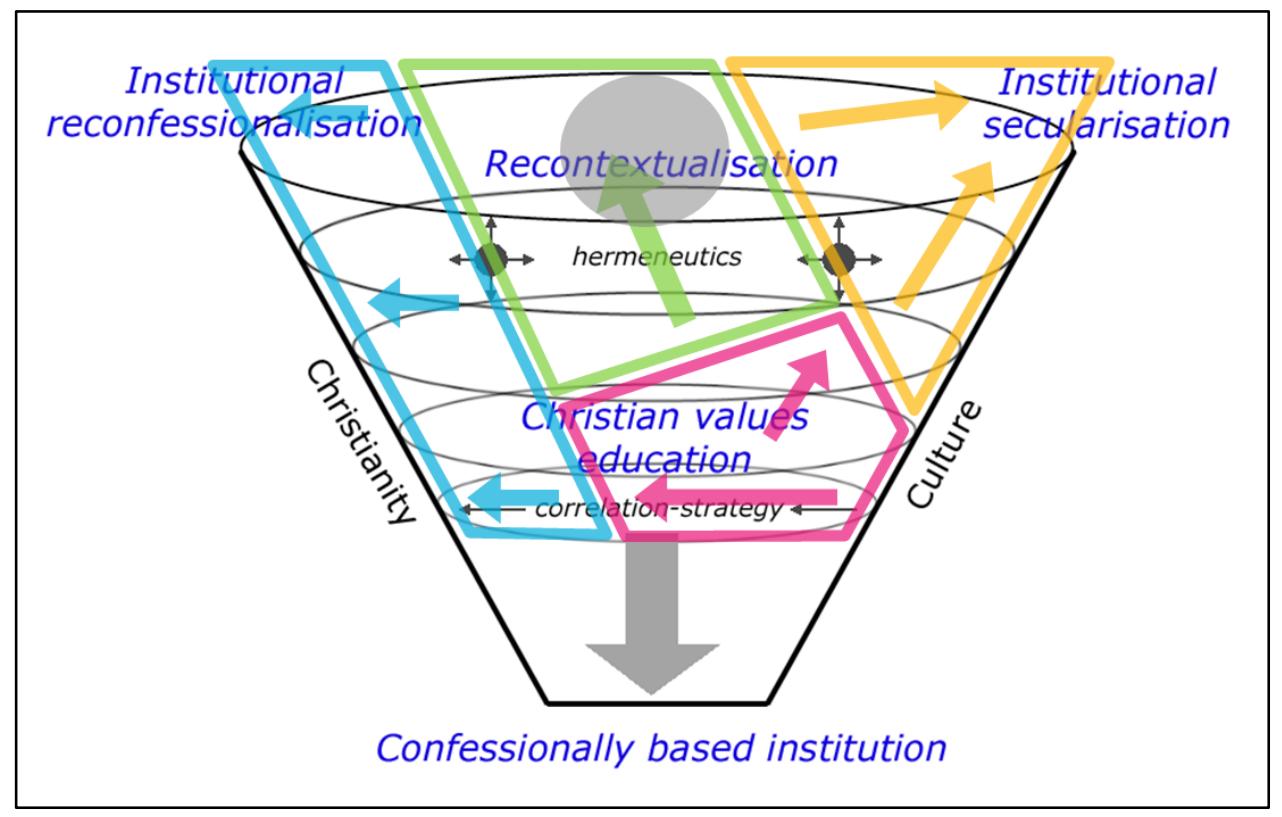

Figure 4: (C) Pollefeyt \&

Bouwens 2018

Figure 4 shows the four subpopulations plotted on a diagram of a 'cone' which simultaneously depicts the widening gap between Christianity and culture over time. Reconfessionalisation and Secularisation are seen on the two sides of the cone, with their allegiances being respectively to Christianity or culture. A Confessionally-based institution relates Christianity to culture quite closely in the 1950s. CVE is plotted as a strategy of the 1970s and 1980s, when the cone is widening but when the gap in the middle is still not too large. As time moves on, at the top of the cone, we see that Recontextualisation is seen as a strategy to enable some dialogue between Christianity and culture, which are now seen to be widely divergent.

Figure 5 shows the normative results for the four subpopulations on the Melbourne Scale diagram. Results for staff at primary and secondary levels are split and shown on the top of the two levels of Figure 5. While there are not insignificant levels of support for Secularisation and Reconfessionalisation amongst staff members, especially at secondary school level, what is of most interest are the results for CVE shown in the pink area. Over one third of school staff support CVE. The arrow shows that their possible intention is to use CVE to support the Reconfessionalisation of the school. However, when we consider the results for students at primary and secondary levels, 
which are split and shown on the bottom of the two levels of Figure 5, we see that a similar level of support for CVE shows the likely intention of these students is to use CVE to support school Secularisation. While the staff using CVE may have positive or neutral intentions for the Catholic identity of the school, the effect on the students is negative.

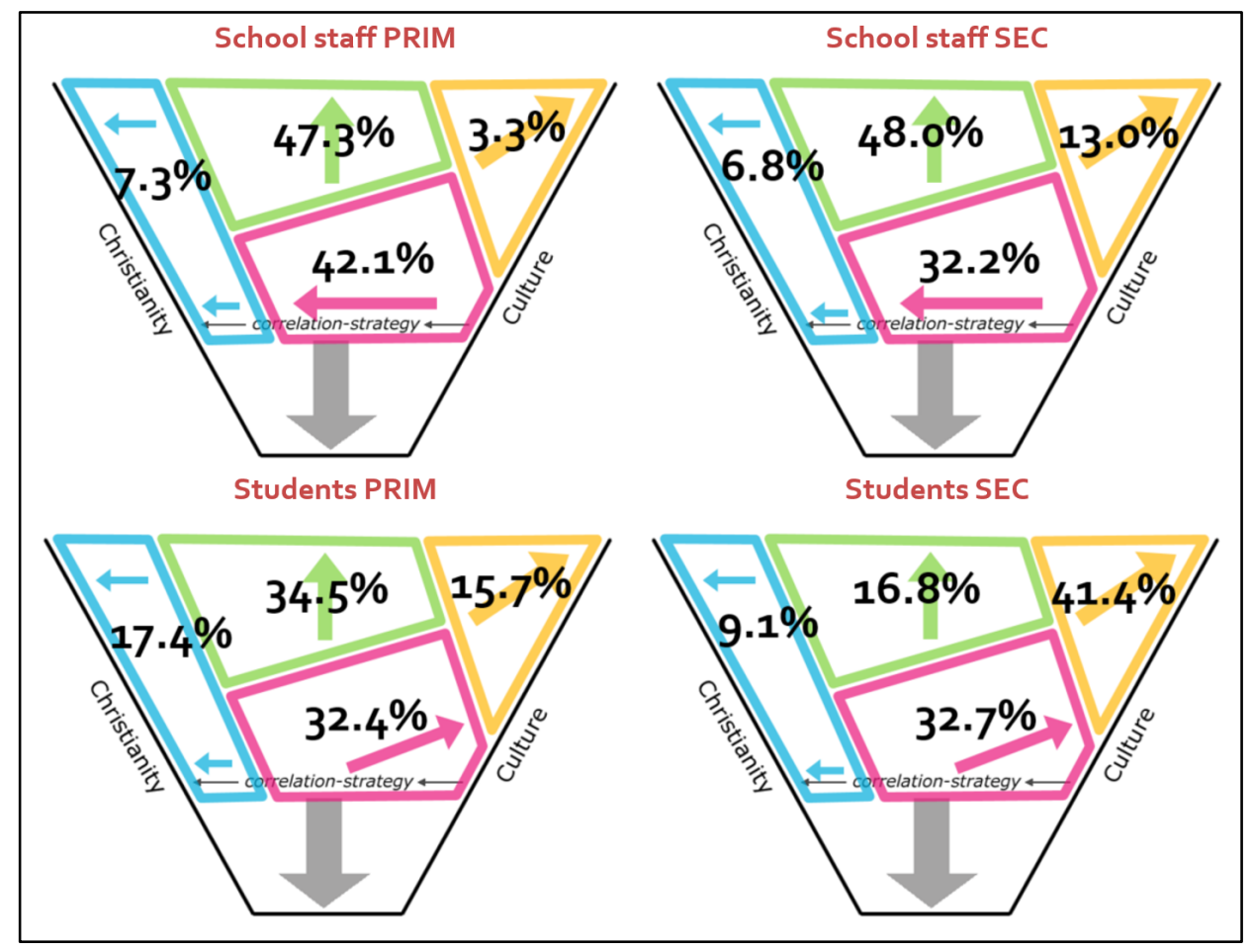

Figure 5: @ Pollefeyt \& Bouwens 2018

The ECSI research demonstrates that how staff approach Catholic identity really matters. Evidently, staff who support the Secularisation of the school should really think about the nature and purposes of Catholic schooling from a Church perspective and discern their capacity to support this purpose. Similarly, given its effects on the students, staff taking a Reconfessionalising approach should reconsider their stance. Most significantly, however, if staff members approach Catholic identity from a perspective of CVE-even if we interpret their having the most optimistic of intentions - the data shows that their strategy effectively results in the gradual but inevitable Secularisation of their schools. While the research also identifies a way out of this impasse-a Recontextualisation of Catholic identity based on Post-Critical Belief through dialogue with the context-this brings to the fore the importance of a reflexive engagement with questions of faith on the part of the teachers.

\section{Faith Dispositions and Teachers in Catholic Schools}

In keeping with the values of academic and personal freedom, the preparation of teachers for and in their work in Catholic schools is often distanced from their privately held views and beliefs. At the same time, however, the data above suggest that how teachers are disposed towards Catholicism 
is crucial to their support of the identity of a Catholic school, particularly (although not only) in the RE classroom. ${ }^{18}$ This is in two respects: first, in relation to their knowledge and understanding of the Catholic religious tradition; and second, in relation to their degree of openness towards faith. These are often interconnected. We argue that all teachers in Catholic schools need a degree of knowledge and understanding of Catholic tradition, as well as a degree of openness towards faith. Teachers of RE need specialist knowledge and understanding of Catholic tradition and a high degree of openness towards faith. One way of thinking about openness towards faith is to describe it as a disposition.

\section{What is a disposition?}

The debate about what dispositions are is ongoing, both philosophically as well as in relation to teacher education. One could venture to say that when it is used of a person, a disposition is a quality of being-toward something or someone that will potentially be manifest in particular circumstances. To say that someone has a sunny disposition is often used to mean that this person will, more often than not, appear bright and optimistic in relation to life. According to this way of thinking, then, a disposition would be a type of intentionality. ${ }^{19}$ In fact, in contemporary philosophy, faith itself can be considered intentional in this way. ${ }^{20}$ The controversy about dispositions, however, continues, since questions are frequently raised about the extent to which dispositions are reliably observable. This relates both to their hidden nature and to the fact that they are often described as potential rather than actual (Tim Crane gives the impersonal example of glass, which is dispositionally fragile; its fragility is only actual in the event that it shatters). Moreover, behaviours in any given context cannot always prove the existence of a particular disposition (the offering of a gift from one person to another might suggest but does not prove that the giver has a loving disposition). ${ }^{21}$

In the educational literature, it has been argued that the language of dispositions is unhelpful. ${ }^{22}$ This is because dispositions are often linked with belief-perspectives, so that they can appear to be no more than knowledge; because linking dispositions with personality traits obscures the fact that dispositions can be chosen or learned; and because trying to assess dispositions on the

\footnotetext{
${ }^{18}$ See Linda E. Martin and Thalia M. Mulvihill, "Voices in Education: Professional Dispositions in Teacher Education," The Teacher Educator 52, no. 3 (2017).

${ }^{19}$ Tim Crane, ed. Dispositions: A Debate: D.M.Armstrong, C.B.Martin, and U.T.Place (London: Routledge, 1996$), 8$.

20 Jean-Luc Nancy, Dis-Enclosure: The Deconstruction of Christianity, trans. Bettina Bergo, Gabriel Malenfant, and Michael B. Smith (New York: Fordham University Press, 2008), 52.

${ }^{21}$ See, for example, the editor's introduction in Crane, Dispositions: A Debate: D.M.Armstrong, C.B.Martin, and U.T.Place.

${ }^{22}$ Terry Burant, Sharon Chubbuck, and Joan Whipp, "Reclaiming the Moral in the Dispositions Debate," Journal of Teacher Education 58, no. 5 (2007). On assessement, see Frances C. Welch et al., "Significant Issues in Defining and Assessing Teacher Dispositions," The Teacher Educator 45, no. 3 (2010).
} 
basis of observable behaviour is fraught. One group of authors suggest that instead of teachers being required to develop particular dispositions, they should be encouraged to develop "moral sensibility." ${ }^{23}$ Nevertheless, an understanding of dispositions may be helpfully appropriated from theology. Edward Farley describes the translation of Aristotle's thought into theological terms in the $13^{\text {th }}$ century: "they portrayed knowledge (scientia) as a habit, an enduring orientation and dexterity of the soul. It was natural then to see theology as a habitus, a cognitive disposition and orientation of the soul, a knowledge of God and what God reveals." 24 While this might appear-as per the argument above-to elide the difference between knowledge and dispositions, recent research on affective knowledge suggests that such an elision need not be the case. ${ }^{25}$ What it suggests, instead, is that dispositions may be prepredicative and need to be brought to the surface or translated by means of critical reflection. In terms of assessment, becoming cognisant of dispositions may require teacher educators to "sit with and accompany learners while they are learning rather than simply apply some form of measurement at an end point to determine whether they have indeed learned." 26

\section{Faith as a Disposition}

A study by Hazel Bryan and Lynn Revell examines the relationship between student-teachers' faith and required teacher dispositions as they are outlined in the United Kingdom (UK) Teaching Standards. ${ }^{27}$ We note that the UK context involves both a national religion as well as a commitment to non-confessional RE. ${ }^{28}$ The Bryan and Revell study investigates the extent to which Christian student teachers in Britain felt compelled to withhold their personal faith position from school students in teaching RE. This felt compulsion was based on a reading of the Teaching Standards that emphasised the values of teacher neutrality and objectivity, and an assumption that the Standards themselves were similarly neutral and objective. The authors observe: "The source of the tension for these students was that they regarded the values embodied in the Standards as legitimate, and

\footnotetext{
${ }^{23}$ Burant, Chubbuck, and Whipp, "Reclaiming the Moral." The authors' difficulties with the two professional standards documents they discuss might be resolved with reference to the ethical dimensions of behaviour found in National Council for Accreditation of Teacher Education, "Professional Standards for the Accreditation of Teacher Preparation Institutions," (Washington, DC: National Council for Accreditation of Teacher Education, 2008), 22n15.

${ }^{24}$ Edward Farley, Theologia: The Fragmentation and Unity of Theological Education (Minneapolis, MN: Fortress Press, 1983), 39.

${ }^{25}$ Robyn Horner, "Words that reveal: Jean-Yves Lacoste and the experience of God," Continental Philosophy Review, no. 51 (2018); "Is Anxiety Fundamental? Lacoste's Reading of Heidegger " New Yearbook in Phenomenology and Phenomenological Philosophy (2020 forthcoming).

${ }^{26}$ Burant, Chubbuck, and Whipp, "Reclaiming the Moral," 17.

${ }^{27}$ Hazel Bryan and Lynn Revell, "Performativity, Faith and Professional Identity: Student Religious Education Teachers and The Ambiguities of Objectivity," British Journal of Educational Studies 59, no. 4 (2011).

${ }^{28}$ See L. Philip Barnes, "The 2007 Birmingham Agreed Syllabus for Religious Education: a new direction for statutory religious education in England and Wales," Journal of Beliefs \& Values 29, no. 1 (2008).
} 
[perceived] that the values themselves were, in essence, value free." ${ }^{29}$ Students did not discern, in other words, that the Standards unreflectively assume and depend on secular values. They internalised "the idea of the good teacher as someone who was, by very definition, neutral and objective," and then inferred that their possession of Christian faith could only be interpreted and lived negatively, as a kind of infraction. In striking contrast, atheist and agnostic students "felt no contradiction in articulating their own values in the classroom, while at the same time believing that they were value-free." 30 This finding is reinforced in a Norwegian study showing that "Religious Education teachers 'distinguish strongly between their personal view and their role as teachers in Religious Education'," and that "this seems particularly to be the case with the teachers with a religious world view, not so much with the secular humanist ones." 31

In some instances, theoretical reflection on RE as a discipline discredits confessional dispositions and formalises the concealment of a teachers' personal appropriation of faith. Bryan and Revell refer to the ways in which the discomfort of the Christian student teachers in revealing their faith perspectives may have been reinforced by "the nature of many of the guidelines and policies that inform the teaching of RE more specifically." They cite Trevor Cooling, who analyses curricular assumptions that "undermine or marginalise," he argues, "the position of faith within RE." ${ }^{32}$ Cooling traces this approach to Paul Hirst, who argued in the 1970s that RE should consist in the objective study of religion. ${ }^{33}$ We see this 'objective' approach in Ninian Smart's work in RE, which was at the forefront for many years in the UK and has been a strong influence on Australian curricula, as can be seen in the "educational" approach, which "place[s] emphasis on the educational components of religious studies within the curriculum," although it is sometimes understood as a vehicle allowing for (or at least, not excluding) dimensions of faith formation. ${ }^{34}$ Smart's phenomenology requires the bracketing of the teacher's faith position in attempting to present religious traditions fairly in their plurality, the aim being to enhance mutual understanding and interreligious tolerance. His work was criticised for this emphasis on artificial neutrality. ${ }^{35}$

\footnotetext{
${ }^{29}$ Bryan and Revell, "Performativity, Faith and Professional Identity," 414.

30 Ibid., 414, 16.

${ }^{31}$ Geir Skeie, "Impartial teachers in religious education - a perspective from a Norwegian context," British Journal of Religious Education 39, no. 1 (2017).

32 Bryan and Revell, "Performativity, Faith and Professional Identity," 414.

${ }^{33}$ Trevor Cooling, "Faith, religious education and whole school issues," in Debates in Religious Education, ed. L. Philip Barnes (London: Taylor and Francis, 2011), 90.

${ }^{34}$ Barnes argues that there were many others who contributed to the development of a phenomenological approach in $\mathrm{RE}$, not all were faithful to Smart's vision of phenomenology. See ibid., 88-97, 90. On the educational approach, see Michael Buchanan, "Pedagogical Drift: The Evolution of New Approaches and Paradigms in Religious Education," Religious Education 100, no. 1 (2005): 32-33, 33.

${ }^{35}$ Kevin O'Grady, "Professor Ninian Smart, phenomenology and religious education," British Journal of Religious Education 27, no. 3 (2005).
} 
However, we note the strong emphasis on "inclusive" RE found both in Smart, and in the more recent work of Robert Jackson. ${ }^{36}$ In Jackson's view, RE demands a disposition of impartiality (instead of neutrality) on the part of the teacher. Jackson does not exclude the possibility that teachers of RE will possess particular faith perspectives, but argues that these must be significantly tempered if the teacher is to be effective. ${ }^{37}$

The marginalisation of a disposition of faith for religious educators is evident in the Australian Catholic school context, which differs from the UK context in a number of important respects. ${ }^{38}$ With regard to Thomas Groome's kerygmatic approach to teaching RE ("Shared Christian Praxis"), Terry Lovat writes in the 1980s: "While Groome's is, in my opinion, by far the most admirable faithforming RE model available today because of its educational and theological precision, it is nonetheless burdened with some of the weaknesses of any model whose goal is, in a fairly direct way, to form and inform faith." ${ }^{39}$ In some Australian models, a distinction is drawn between "teaching people religion and teaching people to be religious in a particular way." 40 This distinction has its origins in the "reconceptualist" approach of Gabriel Moran and Maria Harris, and likely reflects something of the controversy about teaching religion in the United States. ${ }^{41}$ According to this approach, RE (as distinct from community activities such as prayer and liturgy) is to be understood as a purely academic study.

Now, the very real advantages of a reconceptualist model include that it can foster appropriate respect for students' own beliefs and perspectives; avoid any charge of indoctrination in the academic curriculum; speak to a contemporary context which is secularised, pluralised and detraditionalised; receive appropriate recognition and a degree of legitimacy in the eyes of the state; meet government policies such as those requiring reporting on student achievement in RE in

\footnotetext{
${ }^{36}$ Robert Jackson, "Inclusive Study of Religions and World Views in Schools: Signposts from the Council of Europe," Social Inclusion 4, no. 2 (2016); Robert Jackson and Judith Everington, "Teaching inclusive religious education impartially: an English perspective," British Journal of Religious Education 39, no. 1 (2017).

37 "Teaching inclusive religious education impartially," 14-16.

${ }^{38}$ These differences include the fact that there is no national religious identity in Australia, and that RE does not feature as part of the years Foundation-10 state curriculum in any jurisdiction. In Australia, RE features predominantly in religiously-affiliated schools as part of the curriculum and Catholic schools not only make up 19.9 per cent of these schools but also devote the most amount of time to classroom RE.

${ }^{39}$ Terence J. Lovat, "Action Research and the Praxis Model of Religious Education: A critique," British Journal of Religious Education 11, no. 1 (1988): 36. This is in spite of the observation: "RE from an educational perspective did not exclude the faith-forming dimension of RE, which underpinned the doctrinal, kerygmatic, life-centered, and shared Christian praxis approaches. It did, however, emphasize that, within the formal RE classroom, the educational perspective was paramount." Kathleen Engebretson, Joe Fleming, and Richard Rymarz, eds., Thriving as an RE Teacher: A Handbook for Secondary Religious Educators (NSW: Social Science Press, 2002), 11.

${ }^{40}$ Gabriel Moran, "Understanding Religion and Being Religious," Professional Approaches for Christian Educators (PACE) 21 (1991): 249.

${ }^{41}$ Kieran Scott, "Three Traditions of Religious Education," Religious Education 79, no. 3 (1984): 333-37. School District of Abington Township, Pennsylvania v. Schempp, 374 U.S. 203 U.S. Reports (1963).
} 
terms of knowledge and skills; and deal with the increasing situation where teachers themselves have no particular religious commitment. On this way of analysing the situation, teacher dispositions for RE in confessional schools can be articulated in terms consonant with, if not identical to, the terms used for teacher dispositions in other disciplines and in state schools. The faith disposition of the teacher is downplayed because it can be perceived to be inappropriate or indoctrinating. The emphasis is instead placed on the teacher as someone who possesses professional expertise in the subject area. ${ }^{42}$

In a Catholic school, however, the problem with the Moran approach is precisely in the dispositional requirements of the RE teacher. ${ }^{43}$ Considering this issue from the point of view of contemporary phenomenology assists us to think further about its implications. A genuinely phenomenological approach cannot assume that the question of God is simply a question about belief and that it has always and already been decided in the negative. The bracketing of "the natural attitude" actually requires an open mind as to what can give itself. ${ }^{44}$ If the person "teaching people religion" approaches religious phenomena as if they have no reality, or as if each religious phenomenon has the same kind of reality (which comes to the same point), the approach effectively distorts the phenomena by emptying them in advance of something they are purported to have, that is, a confessional reality and thus a content or meaning opposed to neutral or impartial rationality. Even Jackson recognises aspects of the difficulty: "We acknowledge that a teacher exhibiting a form of atheism which regards not only religions, but the study of religions as worthless pursuits ... would not be able to function effectively as an educational professional in this field." 45

\footnotetext{
${ }^{42}$ In a rare piece of research on professional standards in RE, the authors only obliquely refer to the faith disposition of the teacher in noting that "all but one of the graduate teachers expressed enthusiasm for their RE teaching because of their own Catholic background and education, their personal religious beliefs, their enjoyment of the students, and various other reasons." At the same time, in the draft list of standards the authors produce, in the area of "professional knowledge," teachers are to be "aware that RE is not an exercise in talking about their own beliefs" (read positively: RE is not an exercise in teachers speculating in an uninformed way about theological questions, RE is not an exercise in teachers wasting class time by focusing on themselves, and RE is not an exercise in indoctrinating students; read negatively: RE does not have anything to do with the faith disposition of the teacher), and in the area of "professional values," teachers must "[believe] in the value of the RE curriculum ... [and be] committed to the task of RE" - neither of which link teaching RE to a faith disposition, but only to values associated with the teaching of RE. Kath Engebretson and Jan Grajczonek, "Professional Standards for Graduate Teachers of Religious Education in Catholic Schools: Implications for Teacher Preservice Education," Journal of Religious Education 60, no. 2 (2012): 33, 34.

${ }^{43}$ Michael Buchanan, "Factors that Impede Curriculum Change: A Preliminary Report," British Journal of Religious Education 28 (2006).

${ }^{44}$ Robyn Horner, "Towards a Hermeneutic-Phenomenological Methodology for Theology," International Journal of Practical Theology 22, no. 2 (2018).

45 Jackson and Everington, "Teaching inclusive religious education impartially," 9 (Jackson and Everington here cite A.C. Grayling, "Those Who Defend Religious Studies Do So Only because of Vested Interests," Times Education Supplement: Opinion, March 4, 2015, and Robert Jackson, "A C Grayling Is Wrong. RE and Philosophy Are Complementary, Not Alternatives," Times Educational Supplement: Opinion, March 2, 2015).
} 
Moreover, the phenomenon to which a teacher of RE refers appears differently according to its resonances within a tradition of interpretation. To use a non-Christian example, the famous big rock at the centre of Australia is both a geological feature ("Ayer's Rock") and a sacred phenomenon ("Uluru"). Even a person sensitive to the experience of Australian indigenous people will not 'see' the sacredness of Uluru. Similarly, while a sensitive person teaching RE in a Catholic context can be respectful, for example, of the sacredness of the eucharistic elements 'for Catholics,' only the person who actually lives within the dynamic of the Christian story can make visible this sacredness in their attestation to it. In the words of the recently published (Australian) National Catholic Education Commission Framing Document-RE: "RE is rich and authentic when the teacher witnesses to a living faith that invites students to discipleship and mission." ${ }^{46}$ At the same time, we would not wish to suggest that such attestation can only be strictly singular or that such an invitation become coercive. ${ }^{47}$

Evidently, this way of understanding religious phenomena has a significant impact where it comes to considering the possibility of a Catholic school as authentically dialogical. It could be argued that the teacher exhibiting a Christian faith disposition has effectively excluded the reality of other religious phenomena or the potential validity of other worldviews. This is, in one sense, true. However, there is no such thing as a generalised religion or religious attitude (we learn about faith-as distinct from "religion" - by participation in its particularity). Teachers of RE in Catholic schools need to be able to make Christian phenomena visible in an authentic way, but it is also incumbent upon them to develop knowledge and understanding of traditions and worldviews that they do not share. It is equally vital that where those traditions and worldviews exist within the school and the classroom, they are able to speak for themselves in a space that is well moderated. Being inclusive is necessary if a school aims to be a dialogue school, especially when motivated by a Catholic religious point of view. It can be an asset if the diversity among the teaching staff mirrors the diversity among the student population. This is helpful if the dialogue is to be horizontal and vertical, two directional and asymmetrical at the same time.

To separate RE from the prayer and liturgical life of the school, as Moran suggests, raises further questions about the accountability of Catholic schools to the Church in terms of "the faith development dimension of the student's learning." ${ }^{48}$ Such accountability is important in terms of

\footnotetext{
${ }^{46}$ National Catholic Education Commission, Framing Document - Religious Education (National Catholic Education Commission, 2017-18), 15.

${ }^{47}$ Didier Pollefeyt, "Difference Matters: A Hermeneutic-Communicative Concept of Didactics of Religion in a European Multi-Religious Context," Journal of Religious Education 56, no. 1 (2008): 15-16.

48 Moran, "Understanding Religion and Being Religious," 249.
} 
the Church's vision of the Catholic School as an educational community offering a formative experience of Christian faith. That is not to argue that actually committing to Christian faith is a requirement for all teachers in Catholic schools; neither is it to say that RE should be undertaken with a catechetical approach, which would be monological and reconfessionalising. ${ }^{49}$ However, we argue that providing all teachers with the opportunity to reflect on and to develop dispositions of openness appropriate to teaching in Catholic schools is crucial. While it would be inappropriate to test a teacher's faith disposition, it is important to bring it into view so that personal authenticity and credibility undergirds the commitment to working in a Catholic school. This is most especially the case for teaching RE. "Religious educators," Pollefeyt argues, "must have something to say about the Christian tradition and the way they have integrated it in their own lives and the community." 50

Conclusions

In the present article we have argued that in the contemporary cultural context, it is difficult for Catholic schools to maintain a traditional understanding of their role in the formation of students' (Catholic) faith. The rise of "no religion" in the West reflects the fact that we live in largely secular contexts, which are pluralised and detraditionalised. Consolidated ECSI data reveals that students have little to no appetite for an evangelising agenda in Catholic schools, and often favour approaches to RE that do not demand any sort of personal engagement. This is sometimes unintentionally supported by staff. While many staff members are open to a recontextualising approach, there is a significant proportion who reinforce CVE, which has a secularising effect. This forces the issue of the importance of teacher dispositions in maintaining or enhancing the Catholic identity of the school. We argue that openness to faith is a dispositional requirement of teachers in Catholic schools, and that this requires a capacity, above all, to be self-reflexive in responding to questions of faith.

\footnotetext{
${ }^{49}$ See Graham M. Rossiter, "The need for a "creative divorce" between catechesis and religious education in Catholic schools," Religious Education 77, no. 1 (1982).

${ }^{50}$ Didier Pollefeyt, "The Lustre of Life: A Hermeneutic-Communicative Concept of Religious Education," Narthex 13, no. 1 (2013): 8.
} 